\title{
Teenage Alcohol Use in the Australian Twin Register: Genetic and Social Determinants of Starting to Drink
}

\author{
A. C. Heath, DPhil and N. G. Martin, PhD
}

\begin{abstract}
Retrospective intormation about teenage alcohol use was obtained from 1589 aduit twin pairs aged $20-30$ years from the Australian twin register. Twin pairs were highly concordant both for teenage drinking (or abstinence) and for early versus late onset of drinking. Sociodemographic variables (e.g., patemal occupation and parental religious affiliation) and psychosocial variables (e.g. personality and attitudinal traits), assessed when the twins were adults, were comparajvely poor predictors of teenage drinking. Environmental influences on onset of drinking appeared to be sez-specific, i.e., uncorrelated ovar twins from unlike-sex pairs. Among drinkers, early versus late onset of drinking was more strongly influenced by inherited factors in temales, but by shared features of the social environment (e.g., (amily background or schoof experience) in males.
\end{abstract}

$T$ HE ONSET OF ALCOHOL USE, like loss of virginity, ${ }^{\prime}$ is arguably one of the major transitions of adolescence..$^{23}$ Loss of virginity and use of marijuana $a^{3-6}$ and of other illicit drugs ${ }^{4.6 .7-8}$ are all much more common among teenage drinkers than among abstainers. The course of development of teenage delinquent behavior is strongly associated with age of onset of alcohol use. ${ }^{3}$ Alcoholrelated problems are also much more common in those adolescents with early onset of alcohol use.'

Most studies of teenage drinking have focused on enviconmental determinants of early versus late age of onset of drinking. Peer pressure or peer approval of drinking have been reported to be important, ${ }^{3.9}$ but this may reflect "assortative friendship," the tendency to select friends similar to oneself in social background and behavior. Contrary to the traditional stereotype of teenage drinking as an act of rebellion, sociodemographic correlates of teenage alcohol use are remarkably similar to those found in surveys of adult drinking patterns. ${ }^{10}$ National surveys of teenage alcohol and drug use in the United States have found that alcohol use is more common in urban than in rural areas, $4.6,11.12$ more common in particular regions of the country (e.g., the North-East rather than the

From the Department of Human Genetics. Medical College of Virzinia, Richmond, Virginia; and the Queensland Institute of Medical Research, Brisbane 4006, Australia.

Received jor publication Octobèr 7. 1987; revised manuscript received March 4. 1988; accepted March 29. 1988.

Data collection was supported by grants from the Australian National Health and Medical Research Council, and the Australian Assaciated Brewers. Data analysis was supponed by ADAMHA Grants AAO6781 ind MH40828, and by N1H Grants AG04954. GM32732. and GM30250.

Reprint requests: Dr. A. C. Heath. Department of Human Genetics.

P. O. Box 33. Medical College of Virginia. Richmond. VA 23298.

Copyright $\bigcirc 1988$ by The Research Society on Alcolioism.
South.11.12, and more common in particular religious groups (e.g., Catholic or Jewish rather than fundamentalist Protestant ${ }^{4.9}$. These same variables are also predictive of adult drinking. ${ }^{13-16}$ Indeed, as Mandell and Ginzburg ${ }^{10}$ hâve notëd, a major predictor of adolescent alcuhol use is parental acceptance of alcohol use.9.17

Surveys of adolescent alcohol use have not addressed the possibility that some teenagers many be especially prone to experiment with alcohol because of predisposing genetic factors. Since personality differences are partly genetic in origin, ${ }^{18}$ genetic influences on onset of alcohol use might be expected if there are associations between personality and alcohol use. ${ }^{3.19}$ It is well established that genetic predisposition affects both liability to alcohol abuse $e^{20-26}$ and individual differences in drinking practices. ${ }^{27-32}$ Do genetic factors also influence onset of alcohol use, or does the influence of genetic predisposition arise only once drinking has started? Do genetic factors influence early versus late age of onset of drinking? To address these questions, we have analyzed data on age of onset of drinking as reported by adult twin pairs participating in a mailed questionnaire survey of an Australian twin sample. ${ }^{30}$

\section{METHODS}

\section{Sample and Measures}

Between November 1980 and March 1982, self-report questionnaires were mailed to all 5967 aduit twin pairs, aged 18 years or greater, enrolled on the Australian National Health and Medical Research Council (NH\&MRC) volunter twin panel. Responses were reccived from 3810 complete pairs of adult twins (1233 female monozygotic 567 male monozygotic, 751 female dizygotic, 352 male dixygotic, and 907 unlikesex dizygotic pairs), giving a 64\% painwise response rate. Although female respondents and monozygotic twin pairs were overrepresented in the sample, a common problem with volunteer twin paneis, ${ }^{33.34}$ and uneducated pairs were underrepresentod, ${ }^{35}$ the sample was found to be representative of the Australian population for measures of personality, symptoms of anxiety and depression, ${ }^{37}$ and weekly alcohol consumption. ${ }^{*}$ A subsample of 100 twins who responded to the main mailing had previously received a pilot version of the questionnaire, on average. 4 months previously. This subsample thus provided us with pilot data

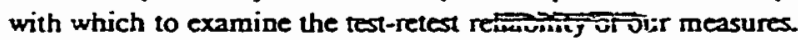

Bocause of our interest in the determinants of toenage drinking, our analyses focused on those twin pairs aged at least 20 years, so that our entire sample had passed through its "period of risk" for toenage drinking. Two items in the quesionnaire asked whether respondents had "Ever taken alcoholic drinks" and "At what age did you start drinking alcohol?" From the answers to these two items. and from the age of the respondent, we were able to classify all respondents as drinkers or abstainers at age 20 . and this is the first variable analyzed here ("teenage abstinence"). 
The second variable, "age staned drinking - is scored for all subjects except those who were still abstainers at age 20 . The use of retrospective quescions about loenage alcohol use had the obvious disadvantage of perruiting errors in recall, but had the advantage of encouraping honest responding even in cases where respondents had started consuming alcobol below the legal drinting age of 18 years. To minimize errors of recall. we excluded from the analysis all twins pairs aged 31 ycars or older. Thus our final sample size was roducod to 1589 twin pairs (480 female monozygotic, 228 male monozygotic, 293 female dizygotic, 170 male dizygotic and 418 unlike-sex dixygotic pairs). A very small number of twin pairs were separated from one another during their childhood (six pairs by age 10, a further 14 pairs by age 14). These numbers were too small to permit analyses of the effocts of separation history. These pairs were therefore combined with pairs reared together throughout their childhood.

In addition to questions about alcohol consumption, respondents were asked to report a variety of-demogenphic information, insluding educational level, frequency of church attendance, father's occupational level, ${ }^{2 *}$ and religious affiliation of self, mother, and father." They also completed the Eysenck Personality Questionnaire, ${ }^{\circ}$ wirt: asesses extraversion, neuroticism, psychoticism (a measure of tough-mindedness), and lie (the tendency to give socially conforming responses); and a version of the Wilson-Patterson Conservatism questionnaire, "modified for use in Australia, ${ }^{22}$ which assesses the conservatism of the respondent's views on a variety of social and political topics (eg., the death penalty, abortion). Only current information, not retrospective information, was sought about these sociodemographic and psychosocial variables. However, evidence for the temporal stability from adolescence into adulthood of at least some of the personality variables (extraversion, neuroticism, psychoticism) is provided by an English study which obtained data both from adolescent twin pairs and their parents, and from adult twin pairs $^{12,43}$ Significant genetic effects were found on these personality variables both in adolescence and in adulthood. Moreover, relatively bigh parent-offspring correlations were obtained, indicating considerable overlap (most markod for neuroticism, least for psychoticism) between the genetic influences in the two generations. Thus, in so far as the same genes are influencing these personality traits both in adolescence and in adulthood, we can predict adolescent personality from personality as sessed in adulthood. For religious affiliation, parent-offspring resemblance was due to environmental rather than genetic factors, but once again the very high parent-offspring correlations found in the Australian survey imply a high degree of continuity from adolescence into adulthood. $^{\text {39 }}$ (Temporal or developmental instability would tend to reduce parent-offspring correlations). These are important considerations when we are attempting to correlate earlier drinking behavior with current psychosocial assessments.

\section{Model-fircing Analyses}

For comparability with other surveys of alcohol use, we have reported all significant associations between teenage drinking and sociodemographic and psychosocial variables. Logistic multiple regression analysis was used to identify predictors of teenage abstinence (a dichotomous variable), stepwise multiple-regression analysis was used for the continuous variable "age started drinking." Our major focus, however, was the resolution of the effects of genotype and shared environment on twin concordance for teenage drinking. The methods of model-fitting by maximum likelihood which we have used are standard statistical methods, so we shall ref-ithe interested readerelsewhere for full technical details 37.4

For tcenage abstinence, which is a dichotomous vaniable, two-way contingency tables were computed, cross-classifying drinking status of first twin at age 20 by the drinking status of the cotwin. (In the case of unlike-sex pairs, the status of the female twin was cross-classified by the status of the male twin.) Genetic and environmental models were fitted to the full set of five twin contingency tables (monozygotic male and female and dizygotic male, female, and unlike-sex pairs) by maximum likelihood." This yiclded an overall $x^{2}$ test of the goodncss-of-fit of each model. The fit of each model was also compared to that of the most general model by likelihood ratio ( $x^{2}$ difference) test. ${ }^{37}$

We have treated reported age of onset as a continuous variable. This is not strictly correct; it is actually a meristic variable, since respondents were asked to report the age at which they started drinking in years, but the approximation to continuity is likely to be good, since the effective number of response categories is large. We have also ignored the problem that in analyzing the determinants of age of onset of teenage drinking. we are necessarily dealing with a truncated sample, since nondrinkers have no age of onset. However, since the percentage of respondents who remainod abstinent through age 20 is small $(<12 \%)$, ignoring this truncation will not seriously bias our inferences about the causes of differences in age of onset in the whole cohort"s

To resolve the contributions of genotype and shared environment to twin resemblance for age of onset of drinking covariance matriceswere computed for each twin group, giving the variances and covariance for age of onset of first and second twins (or female and males twins in the case of unlike-sex pairs). Genetic and environmental modeis were fitted to these by maximum-likelihood covariance structure analysis, weighting each matrix by its degrees of freedom (to take account of the varying sample sizes for male and female pairs, and monozygotic and dizygotic pairs), in the standard manner. $4.46,47$ For each model we thus obtained a $x^{2}$ test of goodness-of-fit, and again compared the fit of the model to that of the most general model by likelihood-ratio $x^{2}$ test.

We wished to resolve four major hypotheses by model-fitting (summarized in Table 1), i.e, that onset of teenage drinking is: (a) environmentally determined, and all environmental influences are uncorrelated over twin pairs (i.e., there is no twin resemblance for teenage drinking: "random environment" model); (b) influenced by both genes and environment, but environmental influences are uncorrelated over twin pairs (so that twin resemblance is entirely genetic in origin: "genetic moded"); (c) environmentally determined, but some important environmental influences are shared by members of a twin pair (e.g., family background. place of schooling, etc: "shared environment" model); or (d) influenced by both genotype and shared environment ("full model"). In testing for genetic effects on teenage drinking, we made the usual assumption that the "environmental" correlation between monozygotic (MZ) twin pairs is no greater than that between dizygotic (DZ) pairs (the validity of this assumption bas been discussed extensively elsewhere ${ }^{\text {ts }}$.

In addition to resolving the effects of genes and environment on onset of teenage drinking, we wished to test for sex differences in the determinants of drinking. We wished to determine whether $(e)$ the effects of random environment shared environment or of genes differ in magnitude in the two sexes (models $2,4,7,10$ in Table 1 ); and especially, $(n)$ whether the correlation between the effects of shared environment in the two sexes (or between genetic effects in the two sexes) is less than unity (models 5, 8, 11). Under hypothesis (e), salient environmental features are cqually shared by trins of the same sex and twins of unlike-sex (such as would be the case for features of family background such as parental drinking habits and attitudes: models 7, 10), or the same genes are important in both sexes (models 4, 10); but their impact on teenage drinking may be greater in one sex than in the other. Under hypothesis $(f)$ environmental effocts are imperfectly correlated in twins of unlike sex, (as would be expoctod if, for example, social influences of same-sex peers are important: model 8); or gene effects in the two sexes are imperfectly correlatod (as may arise if different ger same trait in the two sexes: model 5 ). Information on unlike-sex twin pairs is important in that it allows us to resolve these two hypotheses. Our most general model (model 11 in Table 1) allows for sex-dependent genetic effocts, sex-dependent shared environmental effocts, and a correlation less than unity between shared environmental eflocts in the two sexes It is in theory possible for different sets of genes to be influencing onset in the two sexes, but in practice few such cases have been documented. 


\section{RESULTS}

The test-retest correlation for age started drinking, based on 66 respondents from the pilot sample who were drinkers and reported age of onset on both occasions, was 0.975 (for males: $N=26, r=0.64$; for females: $N=40, r=$ 0.98 ). Thus recall of age of onset appears to be reasonably accurate.

The rates of tee-totalism in the 20-30-year-age group which is the focus of this report are very low $(8.48 \%$ in males, $11.06 \%$ in females), reflecting the widespread acceptance of alcohol consumption in Australia. ${ }^{49}$ Figure 1 plots the cumulative age-of-onset distribution for alcohol use $t_{0}$ age 20 , separately for males and females. A very small proportion of respondents reported use of alcohol but did not start to drink until after age 20 (1.96\% of males, $3.26 \%$ of females). The majority of respondents of both sexes had started drinking by age 17 .

\section{Sociodemographic and Psychosocial Correlates}

Table 2 lists the sociodemographic and psychosocial variables which were predictive of teenage drinking or abstinence; and of early or late onset of drinking. Compared to abstainers, teenage drinkers were more extraverted, less socially conforming, and less conservative. There were no significant differences in toughmindedness or neuroticism. Teenage drinkers were more likely to report their own religious affiliation (females), or the religious affiliation of their mother (males), as Catholic, Church of England or "No religion" rather than "Other Protestant" and they were less regular in their church attendance. Younger respondents were more likely to report that they drank as teenagers than older respondents. No association was found between abstinence from teenage alcohol use and socioeconomic status, whether measured by either father's occupational status, or own educational level, at the time of the survey.

Among teenage drinkers, early onset of drinking was associated in both sexes with lack of conservatism, with social nonconformity, and with maternal or paternal reli-

Tabte 1. Modets for Twin Resemblance for Teenage Drinking

\begin{tabular}{|c|c|c|c|c|}
\hline \multirow[b]{2}{*}{ Model } & \multicolumn{2}{|c|}{$\begin{array}{l}\text { Origins of twin } \\
\text { resemblance }\end{array}$} & \multicolumn{2}{|c|}{ Sex differences? } \\
\hline & $\begin{array}{l}\text { Shared } \\
\text { ervironment }\end{array}$ & $\begin{array}{l}\text { Shared } \\
\text { genes }\end{array}$ & $\begin{array}{l}\text { Ditferences } \\
\text { in } \\
\text { magnitude } \\
\text { of effects }\end{array}$ & $\begin{array}{c}\text { Comelation } \\
\text { between } \\
\text { eflects in } \\
\text { males and } \\
\text { females } \\
<1.0\end{array}$ \\
\hline 1. Random environmemt & No & No & No & No \\
\hline 2. Random entronment & No $=$ & م' م' & Yes & \\
\hline 3. Genetic & No & Yes & No & No \\
\hline 4. Genetic & No & Yes & Yes & No \\
\hline 5. Genetic & No & Yes & Yes & Yes \\
\hline 6. Shared environment & Yes & No & No & No \\
\hline 7. Shared environment & Yes & No & Yes & No \\
\hline 8. Shared emironment & Yes & No & Yes & Yes \\
\hline 9. Fun modef & Yes & Yes & No & No \\
\hline 10. Full modet & Yes & Yes & Yes & No \\
\hline 11. Full model & Yes & Yes & Yes & Yes \\
\hline
\end{tabular}

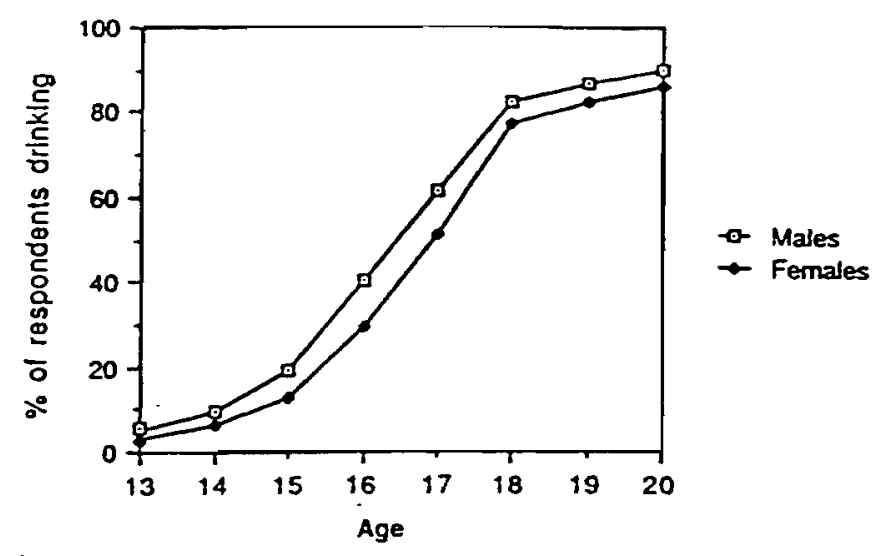

- Fig 1. Cumulative ago of onset distribution tion alcohol use.

. Table 2. Sociodemographic and Psyctosocial Cometates of Teenage Drinking

\begin{tabular}{|c|c|c|c|c|c|}
\hline & \multicolumn{2}{|c|}{$\begin{array}{l}\text { Teenage } \\
\text { drinking/ } \\
\text { abstinence }\end{array}$} & & \multicolumn{2}{|c|}{$\begin{array}{l}\text { Earty onset of } \\
\text { drinking }\end{array}$} \\
\hline & Males & Fernales & & Males & Females \\
\hline Age & $-\cdots$ & $-{ }^{*}$ & Age & $-\infty$ & $-\infty$ \\
\hline Extraversion & $\cdots$ & $\infty$ & Social conformity & $-\infty$ & $-\infty$ \\
\hline Social conformity & $-\cdots$ & $-\infty$ & Conservatism & $-\infty$ & $-\infty$ \\
\hline Conservatism & $-\infty$ & $-\infty$ & $\begin{array}{l}\text { Toughminded- } \\
\text { ness }\end{array}$ & & - \\
\hline Church attendance & $-\cdots$ & $-\infty$ & Education & $-\cdot$ & \\
\hline Rerigion & & - & Patemal reigion & - & \\
\hline Matemal religion & • & & Matemal refigion & & $\bullet$ \\
\hline
\end{tabular}

Significance at the $5 \%(7,1 \%(\%)$, and $0.1 \%$ (") levets in logistic or stepwise muttiple regression analyses. -, low scores associated with teenage drinking.

gious affiliation (in females and males, respectively). In females only, early ofiset of drinking was also associated with toughmindedness. In males, early onset of drinking was also associated with low educational level. The respondent's age at the time of the survey was the single best predictor of reported age of onset of drinking, older females $(r=0.31, p<0.001)$ and males $(r=0.19, p<$ $0.001)$ reporting a later age of onset. In a multiple-regression equation, linear, quadratic, and cubic components of the polynomial regression of age of onset on respondent's age accounted for $9.5 \%$ of the variance in females, and $3.7 \%$ of the variance in males. Since others have reported a trend to earlier onset of teenage drinking (particularly in females) in recent years, ${ }^{50.51}$ these correlations probably reflect a genuine secular trend rather than boasting and exaggeration in younger respondents, but we cannot be sure. Adding sociodemographic and personality variables to age in the multiple-regression equation explained only a further $5.1 \%$ of the variance in females, and $4.2 \%$ of the variance in males. Most of this additional-variance was accounted for by the personality variables $(4.8 \%$ ic males, $3.2 \%$ in males). Overall prediction of age of onset of drinking remained relatively poor.

We found no association between twin zygosity and age of onset of drinking in either sex, nor between zygosity and teenage abstinence. If major differences between zygosity groups had been found, this would have indicated possible sampling biases which might invalidate our model 
fitting analyses, ${ }^{45.52}$ so these nonsignificant results are reassuring.

\section{Genetic Analyses: Teenage Abstinence}

Twin concordances for teenage alcohol use, and the maximum-likelihood estimates of twin tetrachoric correlations $^{53}$ for teenage drinking status (abstainer or drinker), and their standard errors, are given in Table 3. Despite relatively large sample sizes, standard errors are large because of the small number of pairs where one or both twins was still an abstainer at age 20 . Nonetheless, twin resemblance for drinking status was highly significant, pormizting us to reject the "Random Environment": models (models 1 and 2 in Table 1 ).

The results of fitting models to the contingency tables" for drinking status-are summarized in Table 4. Since we have already been able to reject the random environment model, results for models 1 and 2 are not tabulated. All models which ignored sex differences (models 3,6,9) were rejected by $x^{2}$ test of goodness-of-fit. However, there was insufficient power to resolve the "shared environment" model, allowing for different shared environmental effects in the two sexes (model 8), and the genetic model allowing for sex-limited gene action (model 4), with any confidence. Model 8 gave an adequate fit to the data, and was just rejected by likelihood-ratio $\chi^{2}$ test when compared with the fit of the full model $\left(\chi_{2}{ }^{2}=6.14, p=0.05\right)$. Under this model, $62 \%$ of the variance in liability to abstain in females, and $89 \%$ of the variance in males, was attributable to shared environmental effects, but the correlation between the shared environmental effects which are influencing abstinence in the two sexes was estimated as only 0.44 . Model 4 also gave a good fit to the data, and did not give a significantly worse fit than the full model $\left(x_{3}{ }^{2}=\right.$ $3.31, p=0.35$ ). Under this alternative model, $69 \%$ of the variance in females, and $95 \%$ of the variance in males, was due to genetic influences on abstinence. It seems likely that both shared environmental and genetic factors contribute, to differing extents, to abstinence in males and females. Under the full model (model 11), genes and shared environment account for 35 and $32 \%$ of the variance in females, and 47 and $48 \%$ of the variance in males, but the correlation between shared environmental effects in the two sexes is small and indeed negative $(r=-0.11)$.

\section{Age of Onset of Drinking}

Regardless of the cause of the association between age of onset and age of respondent, we are able to remove the effect from our analysis; reported age of onset was corrected for the cubic regression of age of onset on respondent's age at the time of the survey, separately for males and females, prior to genetic analysis. Table 5 gives the covariance matrices for age-corrected age of onset of teenage drinking, for twin pairs where both twins reporned starting to drink as teenagers, i.e., between the ages 13 and 20. Pairs where one or both twins still abstained from drinking at age 20 have been excluded, as have the few pairs where one or both twins reported starting to drink before age 13 . Once again the monozygotic female correlation is not much greater than the dizygotic femalêt correlation $(0.58$ ys_0.42) but_now, the male like-sex_cortelations are of similar magnitude ( 0.52 for male $\mathrm{MZ}$ pairs; 0.54 for male $\mathrm{DZ}$ pairs). As before, the correlation between unlike-sex pairs (0.26) is low, compared to the correlation between like-sex pairs.

Table 6 summarizes the results of fitting genetic and environmental models to the twin covariance matrices. All models which assumed no effect of shared environment on age of onset of drinking (models 3-5) were rejected by $x^{2}$ test of goodness-of-fit. All models which ignored sex differences in the determinants of age of onset (models 3, 6, 9) were also rejected. Model 8, under which twin resemblance for age of onset of drinking is entirely environmental in origin, with a correlation between shared environmental effects in the two sexes of less than unit:; gave an adequate fit to the data. Under this model, $51 \%$ of the variance in age of onset in female twins, and $52 \%$ of the variance in male twins, is attributable to shared environmental effects, but the correlation between sexes for these effects is only 0.48 . However, this nongenetic model gave a significantly worse fit than the full model (model 11), by likelihood-ratio $x^{2}$ test $\left(x_{2}{ }^{2}=8.49, p=\right.$ 0.01 ). Model 10, which allowed for sex-limited effects of both genes and family background on age of onset, but with the same genes and the same features of family background being important in both sexes, gave an excellent fit to the data and did not give a significantly worse fit than the full model $\left(x_{1}{ }^{2}=1.38, p=0.24\right)$. Model 10 is therefore the model which best accounts for our observed data. Under model 10 , genetic effects have no influence on age of onset in males, but account for $44 \%$ of the variance in age of onset in females. Shared environmental effects account for $51 \%$ of the variance in males, but for only $14 \%$ of the variance in females. Thus while there is a strong influence of social environment on the timing of

Table 3. Twin Concordances for Teenage Alcothol Use. and Polychoric Cortelatons

\begin{tabular}{|c|c|c|c|c|c|c|}
\hline $\begin{array}{l}\text { 1st/fernale twin: } \\
\text { 2nd/male twin: }\end{array}$ & $\begin{array}{l}\text { Abstainer } \\
\text { Abstainer }\end{array}$ & $\begin{array}{l}\text { Abstainer } \\
\text { Drinker }\end{array}$ & $\begin{array}{l}\text { Drinker } \\
\text { Abstainer }\end{array}$ & $\begin{array}{l}\text { Drinker } \\
\text { Drinker }\end{array}$ & Pofychoric corretation & Standard error \\
\hline MZ female pairs & 28 & 30 & 31 & 391 & 0.68 & 0.07 \\
\hline$M Z$ male pairs & 17 & 5 & 5 & 201 & 0.95 & 0.03 \\
\hline DZ lemale pairs & 10 & 22 & 18 & 243 & 0.51 & 0.12 \\
\hline DZ male pairs & 4 & 5 & 8 & 153 & 0.67 & 0.15 \\
\hline Unlike-sex pairs & 8 & 29 & 24 & 357 & 0.38 & 0.12 \\
\hline
\end{tabular}


Toble 4. Resurts of Firting Models to Twin Concordances tor Teenage Drinkung Status

\begin{tabular}{|c|c|c|c|c|c|c|c|}
\hline & \multirow[b]{2}{*}{ Moded } & \multicolumn{3}{|c|}{ Goodness-ol-fit test } & \multicolumn{3}{|c|}{$\begin{array}{l}\text { Liketihood-ratio test } \\
\text { (vs. modet i1) }\end{array}$} \\
\hline & & d.t.t & $x^{2}$ & $\rho$ & $\overline{\text { d.f. }}$ & $x^{2}$ & $\rho$ \\
\hline 3 & Generic & 12 & 24.62 & 0.02 & 4 & 15.42 & 0.004 \\
\hline 4 & Genetic + & 11 & 12.51 & 0.33 & 3 & 3.31 & 0.35 \\
\hline 5 & Genetic - & 10 & 12.46 & 0.26 & 2 & 3.26 & 0.20 \\
\hline 6 & Shared environment & 12 & 33.90 & $<0.001$ & 4 & 24.70 & $<0.001$ \\
\hline 7 & Shared environment + & 11 & 24.66 & 0.01 & 3 & 15.46 & 0.001 \\
\hline 8 & Shared ervironment - & 10 & 15.34 & 0.12 & 2 & 6.14 & $<0.05$ \\
\hline & FuA & 11 & 23.18 & 0.02 & 3 & 13.98 & 0.003 \\
\hline & Ful + & 9 & 10.62 & 0.30 & 1 & 1.42 & 0.23 \\
\hline 11 & Fun - & 8 & 9.20 & 0.33 & & & \\
\hline
\end{tabular}

+ model allows for sex differences in the magnitude of genetic or environmenta effects: ". model allows for corretation less than unity between genetic or ervironmental eftects in the two sexes.

t d.f., degrees of freedom.

Table 5. I win Covariance Matrices for Age-Corrected Age of Onset of Alcohol Use

\begin{tabular}{llcc}
\hline & & $\begin{array}{c}1 s t \\
\text { twin }\end{array}$ & $\begin{array}{c}\text { 2nd } \\
\text { twin }\end{array}$ \\
\hline Monozygotic females & 1 st & 1.806 & 0.578 \\
$(N=389)$ & 2nd & 0.965 & 1.641 \\
Monozygotic males & 1 st & 1.957 & 0.515 \\
$(N=187)$ & $2 n d$ & 1.022 & 2.024 \\
Dizygotic females & 1 st & 1.875 & 0.418 \\
$(N=248)$ & $2 n d$ & 0.723 & 1.673 \\
Dizygotic males & 1 st & 2.046 & 0.536 \\
$(N=149)$ & 2nd & 1.100 & 2.228 \\
\hline & & Female & Male \\
& & twin & twin \\
\hline Unlike-sex pairs & female & 1.971 & 0.260 \\
$(N=363)$ & male & 0.526 & 2.108 \\
\hline
\end{tabular}

Twin correlations are given as the upper element of each matrix.

Table 6. Resuts of Fitting Modets to Twin Covariance Matrices for Age of Onset of Teenage Alcohol Use

\begin{tabular}{|c|c|c|c|c|c|c|}
\hline \multirow[b]{2}{*}{ Model } & \multicolumn{3}{|c|}{ Goodness-ot-fit test } & \multicolumn{3}{|c|}{$\begin{array}{l}\text { Wiketinood-ratio lest } \\
\text { (vs. model 11) }\end{array}$} \\
\hline & $\overline{\text { d.f.t }}$ & $x^{2}$ & $p$ & $\overline{\text { d.f. }}$ & $x^{2}$ & $\rho$ \\
\hline 3. Genetic & 13 & 30.15 & 0.004 & 5 & 25.01 & $<0.001$ \\
\hline 4. Genetic + & 11 & 22.93 & 0.02 & 3 & 17.79 & $<0.01$ \\
\hline 5. Genetic * & 10 & 22.08 & 0.01 & 2 & 16.94 & $<0.01$ \\
\hline 6. Shared environment & 13 & 53.53 & $<0.001$ & 5 & 48.39 & $<0.001$ \\
\hline 7. Shared environment + & 11 & 44.71 & $<0.001$ & 3 & 39.57 & $<0.001$ \\
\hline 8. Shared environment - & 10 & 13.63 & 0.19 & 2 & 8.49 & 0.01 \\
\hline 9. Fut & 12 & 26.08 & 0.02 & 4 & 20.94 & 0.01 \\
\hline 10. Fuit + & 9 & 6.52 & 0.69 & 1 & 1.38 & 0.24 \\
\hline 11. Furl- & 8 & 5.14 & 0.74 & & & \\
\hline
\end{tabular}

t. model allows for sex differences in the magritude of genetic or environmental effects: - model allows for correlation less than unity between genetic or shared environmental effects in the two sexes.

td.f. degrees of treedom.

the onset of male drinking, the onset of female drinking is more markedly influenced by genetic differences.

\section{CONCLUSIONS}

Others have reported finding significant associations between onset of teenage drinking and sociodemographic variables such as church attendance and religious affiliation. ${ }^{3.9 .11}$ We were able to confirm these associations in our sample, and to show that psychosocial variables such as extraversion, social conformity and conservatism were also strong predictors of onset of teenage-drinking. Similar correlations were found with age of first sexual intercourse in English twins, ${ }^{\text {ind }}$ andorce the stereotype of the precocious teenagers as outgoing, extraverted, and less restrained by social mores than their peers. Nevertheless, we found that these variables together explained comparatively little of the variance in age of onset of drinking (less than $6 \%$ in either sex).

Abstinence from teenage alcohol use was too rare in our sample to permit clear resolution of its social and genetic determinants by rigorous statistical criteria. This was not unexpected, in view of the widespread acceptance of alsohol use in Australia. ${ }^{49-51}$ However, it seems likely that both genetic and shared environmental factors determine abstinence, although to differing degrees in males and females. What is striking is that those environmental effects which are shared by siblings of the same sex are largely uncorrelated over siblings of opposite sex $(r=0.44$ under model $8 ; r=-0.10$ under model 11 ). Thus those sociodemographic variables which are shared equally by like-sex and unlike-sex siblings (e.g., parental religious affiliation, schooling, or location of home) must be relatively minor determinants of abstinence in Australia. Other sex-specific factors (e.g., influence of same-sex peers) must be important.

When we considered age of onset of teenage drinking, we found no evidence for any genetic influence in males, but a moderate genetic influence in females. Shared environment was relatively unimportant in females, but was having a major effect in males. These findings may be contrasted with the evidence for a quite substantial genetic influence on current average weekly alcohol consumption by this sample (i.e., consumption at the time they completed the questionnaire), in both sexes.30.35 $58 \%$ of the variance in consumption in female twins aged 18-30, and $45 \%$ of the variance in male twins aged $18-30$, was attributable to genetic factors (and 0 and $21 \%$ of the variance to shared environment). Apparently, the effects of genetic predisposition to heavy versus light alcohol consumption only arise once alcohol use has started, and have relatively. little effect on age of onset of drinking. These genetic influences on normal differences in patterns of alcohol use must in turn be largely distinct from genetic influences predisposing to alcoholism-where a greater impact of heredity is observed in males than in females. ${ }^{19-25}$

The sex difference in the determinants of age of onset of teenage drinking which we have discovered may reflect greater acceptance of male drinking than of female drinking among Australian teenagers. ${ }^{17}$ Jessor and $\mathrm{Jessor}^{3}$ found that when a behavior (e.g., marijuana use) is "deviant" in one group (high school students) but not in another (college students), its association with personality variables is much weaker in the latter than in the former group. We have observed essentially this pattern: personality attributes account for $4.8 \%$ of the variance in age of onset of 
females, but only $3.2 \%$ of the variance in age of onset in males. Even though the correlation between personality variables and age of onset was comparatively modest, it must be remembered that we are correlating a measure of current adult personality with reported behavior as a teenager. In view of the substantial evidence for genetic effects on personality, ${ }^{18}$ it is not altogether surprising that we find significant genetic variation in age of onset of drinking in females.

The absence of genetic effects on age of onset in males was unexpected, given the evidence for a highly heritable subtype of alcohol abuse (Cloninger's "male-limited" alcohol abisse ${ }^{19}$ ), expressed primarily in males, and associated with antisocial behavior and early onset of alcohol use. ${ }^{19}$ Such individuals would have been rare in our survey, which used a sample ascertained from the general population rather than from a clinical population; and which. relied on the voluntary cooperation of respondents in completing and returning the self-report questionnaire. If the inheritance of "male-limited" alcohol abuse is polygenic (i.e., involving many genetic loci of small effect ${ }^{54}$ ), however, we would still expect to have included in our sample many individuals intermediate in genetic liability, and therefore we would expect to find evidence for genetic effects on age of onset of drinking. Serious undersampling of such individuals should lead to zygosity differences in mean and variance of age of onset of alcohol use, ${ }^{52}$ differences which we did not observe. It is possible that the inheritance of "male-limited" alcohol abuse is explained by the effects of a relatively small number of genetic loci of large effect ("major gene inheritance"s4), in which case we would not necessarily expect to find genetic effects on age of onset of alcohol use in a clinically unselected population. Alternatively, it may be the case that widespread acceptance of teenage alcohol use in our Australian population has led to a very weak relationship between antisocial behavior and early onset of drinking. More detailed genetic studies of teenage drinking in the Australian population are needed to resolve these possibilities.

Our analyses demonstrate strikingly the importance of familial influences (whether they be genetic or environmental) on teenage alcohol use. Some $51 \%$ of the variance in age of onset in males, and $58 \%$ of the variance in females, is explained by the effects of genes and shared environment. These proportions of variance are an order of magnitude larger than the variance accounted for by measured sociodemographic and psychosocial variables. It seems that the strategy of studying teenage alcohol use off family members, refined by incieasingly detailed measurement of school, home, and peer environmental influences, would greatly improve our understanding of individual differences in teenage alcohol use.

\section{ACKNOWLEDGMENTS}

We thank Dr. John Mathews. Dr. Rosemary Jardine, and Marilyn Olsen for assistance with data collection.

\section{REFERENCES}

1. Martin NG, Eaves U, Eysenck H: Genetical, environmental and personality factors influencing the age of first sexual intercourse in rwins. J Biosoc Sci 9:91-97, 1977

2. Jessor R, Jessor SL: Adolescent development and the onset of drinking: A longitudinal study. J Stud Alcohol 36:27-51, 1975

3. Jessor R. Jessor SL: Problem Behavior and Psychosocial Developmer:: a Longitudinal Study of Youth. New York, Academic Press, 1977

4. Abeison H, Fishburae P, Cisin I: National Survey on Drug Abuse: 1977-A Nationwide Study-Youth, Young Adults, and Older Poople, volume I, Main Findings Washington, DC, U. S. Government Printing Office, 1977

5. Elinson J, Josephson E, Zanes A, Haberman P: A Srudy of Teenage Drug Behavior. Final repori, Naūonal Institute ön Drus T̃buse Grant R01-DA-00043, 1977

6. Miller JD, Cisin IH, Gardner-Keaton H, Harrell AV, Wirz PW, Abelson HI, Fishbume PM: National Survey on Drug Abuse-Main Findings, 1982. Washingion, DC, U. S. Government Printing Office, 1983

7. Kandell DB, Faust $R$ : Sequences and stages in patterns of adolescent drug use. Arch Gen Psychiat 32:923-932, 1975

8. Kandell DB, Kessler RC, Margulies RZ: Antecodents of adolescent initiation to stages of drug use: a developmental analysis, in Kandell DB (od): Longitudinal Research on Drug Use: Empirical Findings and Methodological Issues. Washington, DC, Hemisphere Publishing Corp. 1978, p 73

9. Rachal JV, Maisto SA, Guess LI, Hubbard RL: Alcohol use among Youth. in National Institute on Alcohol Abuse and Alcobolism (ed), Alcohol Consumption and Related Problems. Washington, DC, U. S. Government Printing Office, 1982, p SS

10. Mandell W, Ginzburg HM: Youthful alcohol use, abuse and alcoholism, in Kissin B. Begleiter H (ods): The Biology of Alcobolism, Vol 4, Social Aspects of Alcoholism. New York, Plenum Press, 1976

11. Maddox GL: High school sudent drinking behavior. Incidental information from two national surveys. Quart J Stud Alcohol 25:339347,1964

12. Johnston L O'Aalley PM, Bachman JG: Drug Use Among American High School Students, College Students, and Other Young Adults: National Trends Through 1985. Washington, DC, U. S. Government Printing Office, 1986

13. Riley JW, Marden CF: The social pattent of alcoholic drinking. Quart J Stud Alcohol 8:265-273, 1947

14. Mulford HA: Drinking and deviant drinking U.S.A., 196:. Quart J Stud Alcohol 25:634-650, 1964

15. Cahalan D, Cisin IH, Crossley HM: American Drinking Practices: A National Survey of Behavior and Attitudes. New Brunsuick. NJ, Center of Alcohol Studies 1969

16. Clark WB, Midanik L- Alcohol use and alcohol problems among U.S. adults results of the 1979 National Survey, in: National lnstitute on Alcohol Abuse and Alcoholism (od), Alcohol Consumpion and Related Problems. Washington, DC, U. S. Government Printing Office, 1982, p 3

17. Wilks J. Callan VJ: Drinking habits and alcohol-related keliefs of Austratian, Papua New- Guinean and American youth. Br J Addicz 79:419-424, 1984

18. Eaves U, Young PA: Genetical theory and personaling differences, in: Lynn R (ed): Dimensicns of Personality. Oxford, Pergamon Press, $p 129$

19. Cloninger $C R$ : Neurogenetic adaptive mechanisms in alcobolism. Science (Wash DC) 236:410-415, 1987

20. Kaij, L- Studies on the Etiology and Sequels of Abuse of Alycohol. Department of Psychiatr: University of Lund, Sweden, 1960

21. Gooduin DW, Schulsinger F. Molier N, Hermansen L Winokur G. Guze S: Drinking pattems in adopted and nonadopted sons of alcoholics. Arch Gen Psychiat 31:164-169, 1974 
22. Goodwin DW, Schulsinger F, Knop J, Modnick S, Guxe S: Psychopathology in adoptod and nonadoptod daughters of alcoholics. Arch Gen Psychiat 34:1005-1009, 1977

23. Cadoret RU, Cain CA, Grove WM: Development of aicoholism in adoptecs raisod apart from alcoholic biologic relatives. Arch Gen Psychiat 37:561-563, 1980

24. Bohman M, Sigvardsson S, Coninger, CR: Maternal inheritance of alcohol abuse. Cross-fostering analysis of adoptod women. Arch Gen Psychjat 38:965-969, 1981

25. Cloninger CR, Bohman M, Sigvardsson S: Inheritance of alcohol abuse: Cross-fostering analysis of adopted men. Areh Gen Psychiat $38: 861-867,1981$

26. Schuckit MA, Goodwin DW, Winokur G: A study of alcoholism in half-siblings. Am J Psychiat 128:122-126, 1972

27. Partanen J, Bnun $K$ Markkanen $T$ : Inheritance of Drinking Behavior. New Brunswick, NJ, Rutgers University Center of Alcohol Studies, 1966

- 28. Coderô R, Fñoerg Z, Lundman T: The interaction's of smoking, environment and herodity and their implications for disease aetiology. Acta Medica Scand 202(Suppl 612):1-128, 1977

22. Clifford CA, Hopper JL, Fulker DW, Muray RM: A zenetic and environmental analysis of a twin family study of alcohol use, anxiety and depression. Genet Epidemiol 1:63-79, 1984

30. Jardine $R$, Martin NG: Causes of variation in drinking habits in a large twin sample. Acta Genet Med Gemellol 33:435-450, 1984

31. Kaprio J, Koskeavuo M, Sarna S: Use of alcohol, and leisuretime physical activity amorig same-sexed adult twins, in Gedda L, Parisi P. Nance WE (ods): Twin Research 3: Epidemiological and Cinical Studies New York, Alan R Liss, 1981, p 37

32. Kaprio J, Koshenvuo MD, Langinvainio $H$, Romanov K, Sama S, Rose RJ: Genetic influences on use and abuse of alcohol: a study of 5,638 adult Finnish brothers. Alcohol Cin Exp Res 11:349-356, 1987

33. Lykken DT, Tellegen A, DeRubies R: Volunteer bias in twin research: The rule of two thirds. Soc Biol 25:1-9, 1978

34. Martin NG, Wilson SR: Bias in the estimation of heritability from truncated samples of twins. Behav Genet 12:467-472, 1982

35. Jardine R: A Twin Study of Personality, Social Attitudes and Drinking Behavior. Unpublished PhD thesis, Australian National University, Canberra, 1985.

36. Martin NG, Jardine R: Eysenck's contribution to behavior genetics, in Modgil S, Modgil $C$ (ods): Hans Eysenck: Consensus and Controversy. Lewes, Sussex, Falmer Press, 1986
37. Kendler KS, Heath AC. Marin NG, Eaves, LJ: Symptoms of anxiety and depression in a volunter twin population: The etiologic role of genetic and environmental factors. Arch Gen Psychiat 43:213-221, 1986

38. Congalton AA: Oocupational Status in Australia. Sydney, Unjversity of New South Wales, 1963

39. Eaves $\mathrm{LJ}$, Martin NG, Heath AC: Religious affiliation in twins and their parents: testing a model of cultural inberitance. Behav Gen (in press), 1989

40. Eysenck HJ, Eysenck SBG: Manual of the Eysenck Personality Questionnaire (Junior and Adult). Essex, Hodder and Stoughton Eduational, 1975

41. Wilson GD, Patterson JR: A new measure of conservatism. Br J Soc Clin Psychol 7:1015-1018, 1968

42. Feather NT: Factor structure of the conservatism seale. Aust Psychol 10:179-184, 1975

43. Young PA, Eaves $\mathrm{W}$, Eysenck $H$ : Intergenerational stability and

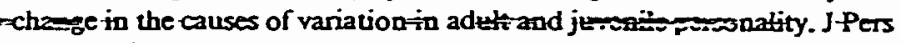
Indiv Diff 1:35-55, 1980

44. Eaves L, Last K, Young PA, Martin NG: Model-fitting approaches to the analysis of human behavior. Heredity 41:249-320, 1929

45. Neale MC, Eaves LJ, Kendler KS, Hewitt JK- Bias in correlations from selected samples of relatives the effects of soft selection. Behav Genet (in press), 1988

46. Joreskog K, Sorbom D: LISREL VI: Analysis of Linear Structural Relationships. Mooresville, IN, Scientific Software Inc, 1985

47. Joreskog K: Structural analysis of covariance and correlation matrices. Psychometrika 43:443-477, 1978

48. Kendler KS: A current perspective on twin studies of schizophrenia Am J Psychiatry 140:1413-1425, 1983

49. Encel S, Kotowicz KC Resler HE: Drinking patterns in Sydney, Australia: Quart J Stud Alcohol (Suppl 6):1-27, 1972

50. Bugey JB, Winter CJ: Alcohol consumption patterns in South Australia: 1983. Mod J Aust 144:6-9, 1986

51. Homel P, Flaherty B: Alcohol use by Australian secondary school students. I Drug Issues 16:199-207, 1986

52. Lykken D, MoGue M, Tellegen A: Recruitment bias in twin research: the rule of two thirds roconsidered. Behav Genet 17:343-362, 1987

53. Olsson U: Maximum likelihood estimation of the polychoric correlation coefficient. Psychometrika 44:443-460, 1979

S4. Elston RC: Major locus analysis for quantitative traits Am J Hum Genet 31:655-661, 1979 